\title{
Comparison of in situ and columnar aerosol spectral measurements during TexAQS-GoMACCS 2006: testing parameterizations for estimating aerosol fine mode properties
}

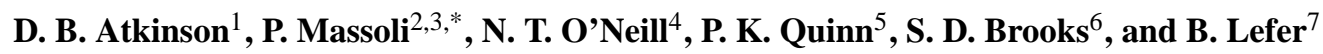 \\ ${ }^{1}$ Chemistry Department, Portland State University, Portland, OR, 97207-0751, USA \\ ${ }^{2}$ University of Colorado, Cooperative Institute for Research in Environmental Sciences, Boulder, CO, 80309, USA \\ ${ }^{3}$ NOAA Earth System Research Laboratory, Chemical Science Division, Boulder, CO, 80305, USA \\ ${ }^{4}$ CARTEL, Département de géomatique appliqueé, Université de Sherbrooke, Sherbrooke, Quebec, J1K 2R1, Canada \\ ${ }^{5}$ NOAA Pacific Marine Environment Laboratory, 7600 Sand Point Way NE, Seattle, WA, 98115, USA \\ ${ }^{6}$ Department of Atmospheric Sciences, Texas A \& M University, College Station, TX, 77843, USA \\ ${ }^{7}$ Earth and Atmospheric Sciences Department, University of Houston, Houston, TX, 77204-5007, USA \\ *now at: Aerodyne Research, Inc. Billerica, MA, 01821, USA
}

Received: 9 July 2009 - Published in Atmos. Chem. Phys. Discuss.: 20 August 2009

Revised: 29 November 2009 - Accepted: 9 December 2009 - Published: 6 January 2010

\begin{abstract}
During the 2006 Texas Air Quality Study and Gulf of Mexico Atmospheric Composition and Climate Study (TexAQS-GoMACCS 2006), the optical, chemical and microphysical properties of atmospheric aerosols were measured on multiple mobile platforms and at ground based stations. In situ measurements of the aerosol light extinction coefficient $\left(\sigma_{\text {ep }}\right)$ were performed by two multi-wavelength cavity ring-down (CRD) instruments, one located on board the NOAA R/V Ronald H. Brown (RHB) and the other located at the University of Houston, Moody Tower (UHMT). An AERONET sunphotometer was also located at the UHMT to measure the columnar aerosol optical depth (AOD). The $\sigma_{\mathrm{ep}}$ data were used to extract the extinction Ångström exponent $\left(\stackrel{\circ}{a}_{\text {ep }}\right)$, a measure of the wavelength dependence of $\sigma_{\text {ep }}$. There

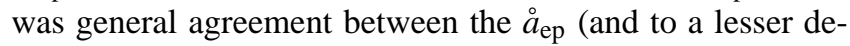
gree $\sigma_{\mathrm{ep}}$ ) measurements by the two spatially separated CRD instruments during multi-day periods, suggesting a regional scale consistency of the sampled aerosols. Two spectral models are applied to the $\sigma_{\mathrm{ep}}$ and AOD data to extract the fine mode fraction of extinction $(\eta)$ and the fine mode effective radius $\left(R_{\text {eff,f }}\right)$. These two parameters are robust measures of the fine mode contribution to total extinction and the fine mode size distribution, respectively. The results of the analysis are compared to $R_{\text {eff,f }}$ values extracted using AERONET V2 retrievals and calculated from in situ particle size mea-
\end{abstract}

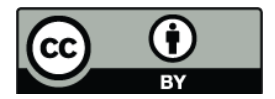

Correspondence to: D. B. Atkinson (atkinsond@pdx.edu) surements on the RHB and at UHMT. During a time period when fine mode aerosols dominated the extinction over a large area extending from Houston/Galveston Bay and out into the Gulf of Mexico, the various methods for obtaining $R_{\text {eff,f agree qualitatively (showing the same temporal trend) }}$ and quantitatively (pooled standard deviation $=28 \mathrm{~nm}$ ).

\section{Introduction}

In its most current report, the Intergovernmental Panel on Climate Change (IPCC, 2007) continues to emphasize the importance of quantifying the connections between aerosols and climate with better precision and accuracy at local, regional and global scales (Andreae et al., 2004; Bates et al., 2006; Lohmann and Feichter, 2005). The accurate estimate of aerosol direct effects due to particle light extinction $\left(\sigma_{\mathrm{ep}}\right)$, scattering $\left(\sigma_{\mathrm{sp}}\right)$, and absorption $\left(\sigma_{\mathrm{ap}}\right)$, where extinction is the sum of scattering and absorption, requires knowledge of the physical and radiative properties as well as the vertical distribution of the bulk aerosol on local to global scales. The aerosol optical depth (AOD), the $\sigma_{\text {ep }}$ integrated along the vertical column, is a key parameter for determining the radiative effects of aerosols (Yu et al., 2006). The AOD is measured on a worldwide scale by networks of ground based spectro-radiometers and sunphotometers, such as the Aerosol Robotic Network (AERONET; (Holben et al., 1998), http://aeronet.gsfc.nasa.gov).

Published by Copernicus Publications on behalf of the European Geosciences Union. 
Cavity ring-down (CRD) spectroscopy (Moosmuller et al., 2005; Strawa et al., 2006; Atkinson, 2003; Baynard et al., 2007) offers robust and precise measurements of the in situ $\sigma_{\text {ep }}$ coefficient. The wavelength dependence of $\sigma_{\text {ep }}$ can be

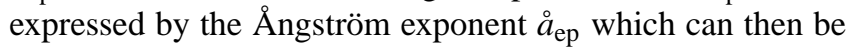
used to infer information about particle size. Values of $\stackrel{\circ}{\mathrm{ep}}_{\mathrm{p}}$ less than one are more likely to be produced by a predominance of coarse mode particles, while values greater than one are more reflective of a predominantly fine mode contribution to aerosol extinction. The $\stackrel{\circ}{A O D}_{\mathrm{AOD}}$, obtained from AERONET sunphotometers, has a similar definition and properties to the in situ $\stackrel{\circ}{\text { ep }}_{\text {p }}$ but is averaged along the vertical path. Recently, satellite retrieval algorithms have been developed to quantify the contribution of the fine mode fraction to the column AOD (Anderson et al., 2005). Such information is critical for models to calculate the climate forcing by anthropogenic aerosols (Chin et al., 2004; Kleidman et al., 2005; Bates et al., 2006; Yu et al., 2006). However, due to the generally high uncertainties of satellite retrievals, those methods are less effective unless supported by in situ measurements. Several types of new low-cost portable instruments have been developed that measure extinction or AOD at multiple wavelengths for radiative effects measurements. These new measurements could be subjected to the data analyses used here and used to provide information about fine mode physical and optical properties on a wider spatial scale than can currently be provided by costlier and more complicated particle sizing instruments.

This work examines the extent to which the spectral information from both in situ and remote instruments can be used to provide information about the fine aerosol mode in the vertical column. We process the $\sigma_{\text {ep }}$ data collected by a three-wavelength cavity ring-down instrument (hereafter the NOAA CRD) using two spectral methods that were developed for the analysis of AOD data to quantify the relative contribution of the fine aerosol mode to the total $\sigma_{\mathrm{ep}}$, referred to as the fine mode fraction of extinction $(\eta)$. These methods also extract the fine mode effective radius $R_{\text {eff, } \mathrm{f} \text {, a }}$ single-parameter characterization of the size distribution for the fine particles. The general definition of $R_{\text {eff }}$ is given by Hansen and Travis (1974);

$R_{\mathrm{eff}}=\frac{\int_{0}^{\infty} r \pi r^{2} \frac{d N}{d \ln r} d \ln r}{\int_{0}^{\infty} \pi r^{2} \frac{d N}{d \ln r} d \ln r}$

where $r$ is the particle radius and $d N / d \ln r$ is the particle size distribution function. Application of Eq. (1) assumes that the fine mode sub-distribution can either be isolated using the spectral information or that one physically divides the radius regime into two segments, for example using a size selective inlet (we investigate both cases in this paper). It has been suggested that variations in $R_{\text {eff,f }}$ are indicative of oxidative aging or cloud processing of anthropogenic aerosols (usually fine mode particles) in the vertical column (Anderson et al., 2005).
Our methods are applied to optical data collected during the 2006 Texas Air Quality Study and Gulf of Mexico Atmospheric Composition and Climate Study (TexAQSGoMACCS 2006), during which the NOAA CRD was deployed on board the NOAA R/V Ronald H. Brown (RHB). A second CRD aerosol extinction instrument was operated by a group from Portland State University (hereafter PSU CRD) atop the Moody Tower builing on the University of Houston campus (UHMT). An AERONET sunphotometer was also located at the UHMT to measure the columnar aerosol optical depth (AOD). The $R_{\text {eff,f }}$ values obtained from the spectral analyses of the CRD data are compared to those derived from sun/sky inversions using the AERONET V2 approach, and to those obtained from mobility size distribution instruments whose data were processed according to Eq. (1). Section 2 provides a detailed description of the experimental data and spectral models used in this study. In Sect. 3, comparisons of the extinction coefficient and $\stackrel{\circ}{\text { ep }}_{\text {measurements from the two }}$ CRD instruments are used to investigate the spatial coherence of the aerosol airmass over the Houston/Galveston Bay area. The comparison of $R_{\text {eff,f from the various methods is }}$ presented for a time period when long-range transported fine mode aerosols dominated the aerosol loading over a large area extending from Houston out in the Gulf of Mexico, and column AOD values measured on board the RHB were high (Massoli et al., 2009). We show that the various methods for obtaining $R_{\text {eff, }}$ agree quantitatively, with a pooled standard deviation of $28 \mathrm{~nm}$. Comparison of the $\stackrel{\circ}{\mathrm{ep}}_{\mathrm{e}}$ and $\eta$ values derived from the CRD instruments is also shown for a time period when coarse aerosols originating from a long range transport of Sarahan dust were present over East Texas.

This work demonstrates that multiple different methods for obtaining $R_{\text {eff,f }}$ show some skill in predicting aerosol physical properties. This implies that ground-based in situ optical measurements may represent a good first approximation of the columnar properties of atmospheric aerosols for validating and constraining satellite retrievals when vertical distribution measurements are not available.

\section{Experimental and theoretical methods}

\subsection{Aerosol sampling and measurement techniques}

Continuous measurements of $\sigma_{\mathrm{ep}}$ were performed during TexAQS-GoMACCS 2006 using two custom CRD instruments operating on separate platforms. A first CRD from Portland State University was located at the $60 \mathrm{~m}$ high Moody Tower building on the University of Houston campus (UHMT) (Lefer and Rappenglück, 2010). The UHMT site housed a suite of instruments for aerosol, gas-phase and meteorological measurements as part of the TexAQS II Radical and Aerosol Monitoring Project (TRAMP). The area surrounding the site is not heavily urbanized, it is approximately one kilometer away from the nearest major traffic 
route to the Northeast, $20 \mathrm{~km}$ from the Houston ship channel (HSC) to the East/North-East, and $4.5 \mathrm{~km}$ from the urban core to the Northwest. Instruments were located inside temperature controlled $\left(24 \pm 2^{\circ} \mathrm{C}\right)$ trailers, and each instrument had its own sample inlet mounted $5 \mathrm{~m}$ above the roof top ( $\sim 70 \mathrm{~m}$ above sea level) to minimize any ground or building interference. Wind speed and direction were measured by various instruments on the building and on the ground. The PSU CRD sampled aerosols through a cyclone impactor (URG Inc., 2000-30EN), and $8 \mathrm{~m}$ of copper tubing was used to transport the sample from the inlet to the CRD instrument. The cyclone has a nominal cut-point of $2.5 \mu \mathrm{m}$ aerodynamic diameter at a flow rate of 10 liters per minute (lpm); however the aerosols were drawn into the PSU CRD at $5 \mathrm{lpm}$, giving a higher cut-point of $4 \mu \mathrm{m}$, according to the URG product literature. The PSU CRD measured $\sigma_{\mathrm{ep}}$ at 532 and $1064 \mathrm{~nm}$, with a maximum time resolution of $0.25 \mathrm{~Hz}$, and a $95 \%$ confidence level detection limit of $4 \mathrm{Mm}^{-1}$ based on previous laboratory data (Radney et al., 2008). The $\sigma_{\text {ep }}$ results presented here are averaged to at least $30 \mathrm{~min}$, resulting in a detection limit of less than $1 \mathrm{Mm}^{-1}$ (Wright et al., 2009).

A Sequential Mobility Particle Sizer (SMPS) (GRIMM Technologies Inc.) was operated at the UHMT site throughout the project. The SMPS consists of a Differential Mobility Analyzer (Model DMA-L) and an Ultrafine Particle Counter (Model 5.403). The SMPS scanned the aerosol particle size distribution from $11.1 \mathrm{~nm}$ to $521 \mathrm{~nm}$ in 38 size bins approximately every $7 \mathrm{~min}$ for the majority of the study period. The size distribution data did not include corrections for variations in shape or density. In addition, a laser-based Aerosol Spectrometer (GRIMM Model 1.108 PAS) recorded a coarse mode particle distribution ( 15 size bins from $0.3 \mu \mathrm{m}$ to $\sim 22 \mu \mathrm{m}$ ) every $60 \mathrm{~s}$. A thorough investigation of this instrument's inlet transmission as a function of particle size allowed for the correction of the raw data for particle losses, which were $\leq 10 \%$ for sizes up to $4 \mu \mathrm{m}$.

An AERONET CIMEL sun/sky radiometer was also located at the UHMT site and was continuously operated during the study period. Level 2.0 AERONET data (cloud screened and quality assured) are used in the analysis presented here. In addition to multi-wavelength AOD and pair-wise $\stackrel{\circ}{a}_{\mathrm{AOD}}$ values, the AERONET V2 data products also include estimates of the particle size distribution and refractive index (Dubovik et al., 2002). This size distribution information is obtained through an inversion algorithm that operates on the full sky scan data (almucantars) combined with near-simultaneously acquired AOD data (Dubovik and King, 2000). The inversion fits the angular and spectrally resolved sky radiance and AOD data to radiative transfer computations derived for a variable (binned) size distribution and variable (pan-radius) refractive index (Dubovik and King, 2000). Non-spherical particle effects are accounted for by introducing a variable fraction of fixed-geometry spheroids (Dubovik et al., 2006; Sinyuk et al., 2007), (see http://aeronet.gsfc.nasa.gov/new/
web/Documents/Inversion/products/V2.pdf). Data products of this method also include the $R_{\text {eff }}$ of the fine and coarse modes and $\eta$ for the AOD.

Aerosols on the RHB were sampled through an inlet (mast) located $18 \mathrm{~m}$ above sea level and forward of the ship's stack. The mast was automatically rotated into the relative wind to maintain nominally isokinetic flow and minimize the loss of super-micrometer particles. Air entered the inlet through a $5 \mathrm{~cm}$ diameter hole, passed through a $7^{\circ}$ expansion cone, and then into the $20 \mathrm{~cm}$ inner diameter sampling mast. The flow through the mast was $1 \mathrm{~m}^{3} \mathrm{~min}^{-1}$. The transmission efficiency of the inlet for particles with aerodynamic diameters less than $6.5 \mu \mathrm{m}$ (the largest size tested) is greater than $95 \%$ (Bates et al., 2002). The bottom $1.5 \mathrm{~m}$ of the mast was heated to establish a stable reference RH for the sample air of $60( \pm 5) \%$. On average, the aerosol was heated $2.5^{\circ} \mathrm{C}$ above ambient temperature. Stainless steel tubes extending into the heated portion of the mast were connected with conductive silicone tubing to downstream instrumentation for aerosol optical property measurements and particle sizing. The NOAA CRD sampled at a rate of $30 \mathrm{lpm}$ off the mast and the light extinction coefficient $\sigma_{\text {ep }}$ was measured at 355, 532, and $1064 \mathrm{~nm}$ in six independent cavities. The NOAA CRD (Massoli et al., 2009) measured the $\sigma_{\text {ep }}$ coefficient for both the sub 1 and sub $10 \mu \mathrm{m}$ sizes (aerodynamic diameter at $60 \% \mathrm{RH}$ at mast outlet) and at different RH conditions (at $25 \%, 60 \%$ and $85 \% \mathrm{RH}$ for the $532 \mathrm{~nm}$, and at $25 \%$ and $85 \%$ for the 355 and $1064 \mathrm{~nm}$ ). The relative uncertainty for $\sigma_{\mathrm{ep}}$ at any wavelength at $25 \% \mathrm{RH}$ is approximately $1 \%$ for data averaged to $1 \mathrm{~min}$, whereas the $\sigma_{\mathrm{ep}}$ coefficients measured at $85 \% \mathrm{RH}$ are characterized by higher relative un-

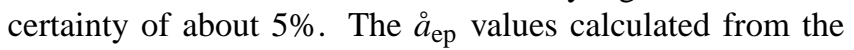
532 and $1064 \mathrm{~nm} \sigma_{\text {ep }}$ coefficients are characterized by an absolute uncertainty of 0.015 if estimated from the $25 \% \mathrm{RH} \sigma_{\mathrm{ep}}$ coefficients, and 0.07 when obtained for $85 \%$ RH conditions (Massoli et al., 2009).

On the RHB, size distributions from 20 to $200 \mathrm{~nm}$ and 200 to $800 \mathrm{~nm}$ in geometric diameter were measured with two parallel differential mobility particle sizers DMPS, University of Vienna (Winklmayr et al., 1991) with short and medium length columns for Aitken and accumulation modes, respectively, coupled to condensation particle counters (CPC model 3760A, TSI, Inc., St. Paul, MN). Size distributions from 0.9 to $10 \mu \mathrm{m}$ in aerodynamic diameter were measured with an aerodynamic particle sizer (APS model 3321, TSI). APS size distributions were converted from aerodynamic to geometric diameters using densities based on the measured chemical composition. More details regarding RHB sizing instruments and data can be found in (Bates et al., 2008; Quinn et al., 2008).

It should be pointed out that although the expressions "fine mode" and "submicron aerosols" are often treated as if they were a interchangeable (likewise for "coarse mode" and "supermicron aerosols") we are aware of the substantial differences regarding how the various measurements and methods 
discussed in this paper obtain the size information: the in situ instruments base such distinction on the aerodynamic particle diameter, usually determined through impaction (Berner et al., 1979). In these cases, the fine mode fraction corresponds to a sub $1 \mu \mathrm{m}$ fraction resulting from an $50 \%$ aerodynamic cut-off diameter within the impactor of $1 \mu \mathrm{m}$ (Doherty et al., 2005; Yu et al., 2006) whereas all of the spectral methods base such distinction on the different optical behavior of small and large particles.

\subsection{Data analysis and spectral methods}

The $\stackrel{\circ}{a}_{\text {ep }}\left(\lambda_{1}, \lambda_{2}\right)$ can be calculated using $\sigma_{\text {ep }}$ values at two different wavelengths $\left(\lambda_{1}\right.$ and $\left.\lambda_{2}\right)$ according to the logarithmic treatment of the assumed power-law expression (Ångström, 1929)

$\stackrel{\circ}{\mathrm{ep}}_{\mathrm{e}}\left(\lambda_{1}, \lambda_{2}\right)=-\ln \left(\sigma_{\mathrm{ep}, \lambda 1} / \sigma_{\mathrm{ep}, \lambda 2)} / \ln \left(\lambda_{1} / \lambda_{2}\right)\right.$.

The PSU CRD $\sigma_{\text {ep }}$ coefficients measured at 532 and $1064 \mathrm{~nm}$ were used to obtain an estimate of $\stackrel{\circ}{\mathrm{ep}}_{\text {for }}$ fore

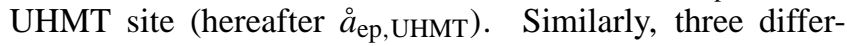
ent $\stackrel{\circ}{\text { ep }}_{\text {ep }}$ values can be obtained pair-wise from the NOAA CRD wavelengths $355,532 \mathrm{~nm}, 355,1064 \mathrm{~nm}$, and 532, $1064 \mathrm{~nm}$ (hereafter $\stackrel{\circ}{\mathrm{ep}}_{\mathrm{RHB}}$ ). Direct comparison between the $\stackrel{\circ}{a}_{\text {ep }, \text { UHMT }}$ and $\stackrel{\circ}{\text { ep }, \text { RHB }}(532,1064 \mathrm{~nm})$ for specific time periods during TexAQS-GoMACCS is presented in Sect. 3.

Next we describe the spectral methods applied to the NOAA CRD and AERONET data to extract the fine mode fraction of extinction $\eta$ and the fine mode effective radius $R_{\text {eff,f: }}$ the Spectral Deconvolution Algorithm with Fine Mode Curvature (SDA/FMC) and the Graphical Spectral Method (GSM). The PSU CRD data were not processed in this way because application of the spectral methods requires data at 3 or more wavelengths.

The SDA/FMC approach (O'Neill et al., 2003; O'Neill et al., 2005) uses the AOD directly measured by the sunphotometer to extract $\eta$ and the Van de Hulst phase shift parameter $\rho_{\text {eff,f }}$ (if a particle refractive index is assumed then $\rho_{\text {eff,f }}$ can be converted to an estimate of $R_{\text {eff,f }}$, cf. Eq. (8) below). This spectral model takes advantage of the higher data density of the direct solar attenuation AOD measurements compared to the full sky scans used by AERONET to extract size distributions, especially with a new high frequency instrument mode which permits the acquisition of AOD data at 3 min intervals.

The SDA/FMC procedure starts with a second order fit of $\ln \left(\sigma_{\text {ep }}\right)$ vs. $\ln (\lambda)$

$\ln \left(\sigma_{\mathrm{ep}}(\lambda)\right)=a_{0}+a_{1} \ln (\lambda)+a_{2} \ln (\lambda)^{2}$.

The three fitting coefficients $a_{0}, a_{1}$ and $a_{2}$ can be used to calculate the $\lambda=1 \mu \mathrm{m}$ extinction coefficient $\left(\sigma_{\mathrm{ep}}=a_{0}\right)$ as well as the extinction Ångström exponent $\alpha_{\text {ep }}$ at any selected wavelength, and its wavelength dependence, the "spectral curvature" $\alpha_{\text {ep }}^{\prime}$

$\alpha_{\mathrm{ep}}(\lambda)=-d \ln \left(\sigma_{\mathrm{ep}}\right) / d \ln (\lambda)=-a_{1}-2 a_{2} \ln (\lambda)$ $\alpha_{\text {ep }}^{\prime}=d \alpha_{\text {ep }}(\lambda) / d \ln (\lambda)=-d^{2} \ln \left(\sigma_{\mathrm{ep}}\right) / d \ln (\lambda)^{2}=-2 a_{2}$.

Note that although we will refer to both $\stackrel{\circ}{a}$ and $\alpha$ as Ångström exponents, they are subtly different in definition and usage: $\stackrel{\circ}{a}$ is an average value for a wavelength range with a proscribed lack of spectral curvature, whereas $\alpha$ is specific to one wavelength (in the sense of a pure derivative); its formulation accounts for higher order spectral curvature, and exploits it to extract further information about the fine and coarse modes. The spectral curvature $\alpha_{\text {ep }}^{\prime}$ value of a finemode dominated distribution increases as $R_{\text {eff,f }}$ increases from $10 \mathrm{~nm}$ to $500 \mathrm{~nm}$, and then decreases for fine-mode particles with radius $>500 \mathrm{~nm}$ (O'Neill et al., 2005; Schuster et al., 2006). For coarse-mode dominated aerosols $\alpha_{\mathrm{ep}}^{\prime}$ is $\leq 0$, an inequality that also applies to very small, absorbing, fine-mode particles (O'Neill et al., 2005). The $\alpha_{\mathrm{ep}}$ and $\alpha_{\mathrm{ep}}^{\prime}$ calculated from both the NOAA CRD $\sigma_{\text {ep }}$ and the UHMT AERONET sunphotometer AOD data are used to extract $\eta$ and the fine mode Ångström parameters at a reference wavelength of $\lambda=500 \mathrm{~nm}$. This information is then used in the

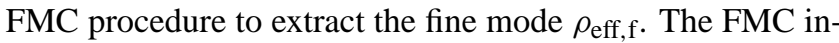
version is based on the observation that the value of $\rho_{\text {eff,f }}$ is a function of the fine mode Ångström exponent $\alpha_{\text {ep,f }}$ and its spectral derivative $\alpha_{\mathrm{ep}, \mathrm{f}}^{\prime}$

$\rho_{\mathrm{eff}, \mathrm{f}}=0.31593+1.25050 \psi+0.52859 \psi^{2}$

where $\psi$ is in radians (Eq. (5) in O'Neill et al. (2005) was incorrectly written and has since been slightly modified to correct for higher-order-polynomial artifacts at the extremes of the $\psi$ range (O'Neill et al., 2008)). From O'Neill et al. (2005) we have:

$\tan \psi=\frac{\alpha_{\mathrm{f}}^{\prime}-0.2}{\alpha_{\mathrm{f}}-0.5}$

The parameters $\alpha_{\mathrm{f}}$ and $\alpha_{\mathrm{f}}^{\prime}$ (outputs of the coarse/fine mode separation in the SDA procedure) are typically characterized by relatively large errors which propagate into the calculation of $\rho_{\text {eff,f. }}$. We have found that these errors are difficult to quantify empirically. They are a significant fraction of the amplitude of $\rho_{\mathrm{eff}, \mathrm{f}}$ but tend to decrease as $\eta \rightarrow 1$. Once the $\rho_{\text {eff,f }}$ has been estimated, the $R_{\text {eff,f }}$ can be calculated according to

$\rho_{\mathrm{eff}, \mathrm{f}}=2\left(2 \pi R_{\mathrm{eff}, \mathrm{f}} / \lambda\right)|m-1|$

where $\lambda$ and $m$ are the reference wavelength and the complex refractive index, respectively. We obtain two $R_{\text {eff,f }}$ values extracted from the SDA/FMC method, one using the AERONET AOD data (hereafter AERONET SDA/FMC) and one from the NOAA CRD data (hereafter CRD SDA/FMC). For the NOAA CRD, only the data collected at $85 \% \mathrm{RH}$ were used to extract $R_{\text {eff,f }}$ via the SDA/FMC approach to best match the sampling conditions at ambient $\mathrm{RH}$ of both PSU CRD and AERONET data. The RH measurements on 

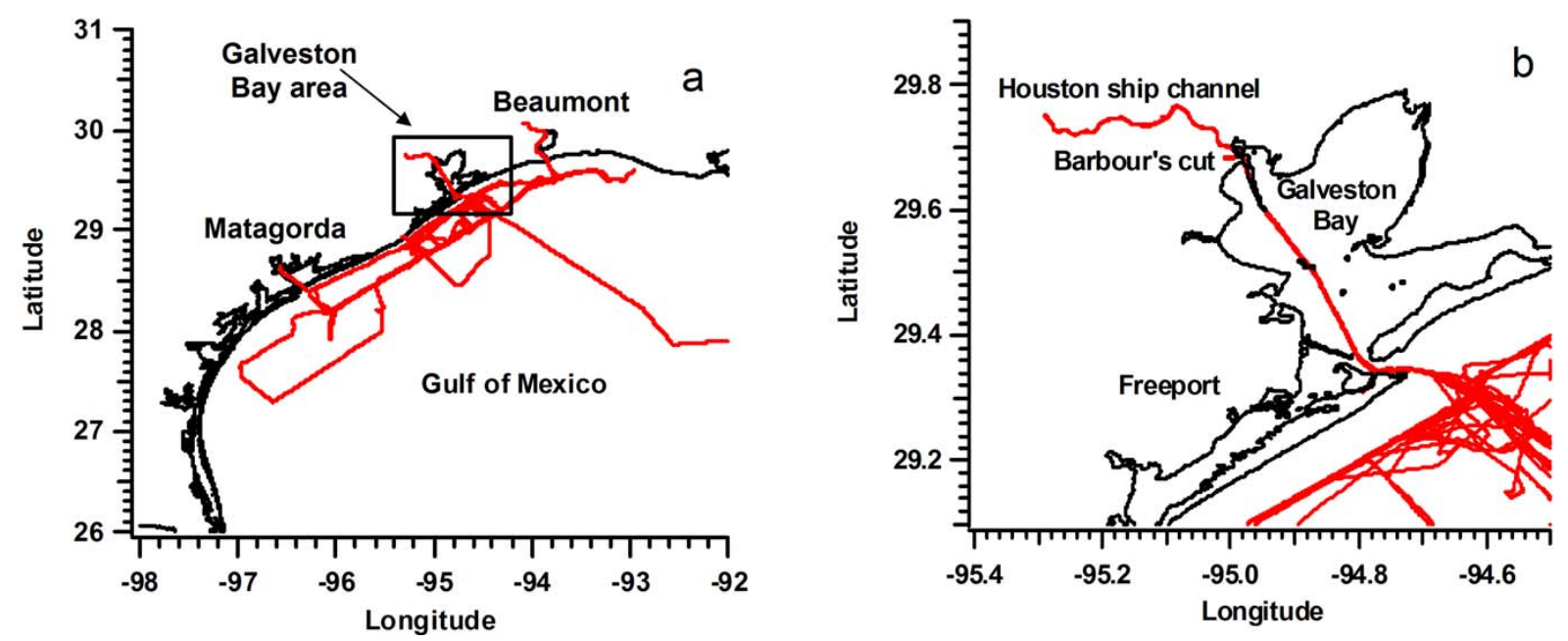

Fig. 1. RHB ship track in (a) the Gulf of Mexico and (b) Galveston bay, during the period 2 August-11 September 2006. The UHMT site is in downtown Houston, about 5 miles east of the Houston Ship Channel (HSC).

the RHB showed that the ambient RH was between 80 and $85 \%$ during most of the study period.

The GSM approach (Gobbi et al., 2007) uses a graphical parameterization of the AERONET products to obtain $R_{\text {eff,f. The method relies on AOD data from three CIMEL }}$ data channels only (unlike the SDA, which uses as many wavelengths as are available) and the data is first screened to remove values below $\mathrm{AOD}=0.1$. The discrete difference of specified pair-wise $\stackrel{\circ}{A}_{\text {AOD }}$ values computed from AERONET sunphotometer data is used to obtain $\delta \stackrel{\circ}{A O D}$

$\delta \stackrel{\circ}{a}_{\mathrm{AOD}}=\stackrel{\circ}{a}_{\mathrm{AOD}}(440,675)-\stackrel{\circ}{\mathrm{aOOD}}_{\mathrm{A}}(675,875)$

which is also referred to as "spectral curvature". Due to a different choice of definitions, the analogous parameter in the SDA/FMC approach $\left(\alpha_{\text {ep }}^{\prime}\right)$ has the opposite sign, so in the GSM method more negative $\delta \stackrel{\circ}{ }$ values will be associated with larger $R_{\mathrm{eff}, \mathrm{f}}$ values. The derived $\delta \stackrel{\circ}{\mathrm{AOD}}$ data are then plotted vs. the $\stackrel{\circ}{a}_{\mathrm{AOD}}$ data on a non-rectilinear grid that was constructed by modeling an extensive set of conditions (see Fig. 1 in Gobbi et al., 2007). Gobbi et al. (2007) demonstrate that the impact of using different atmospherically relevant refractive indices (i.e., different particle compositions) on the retrieval is small. O'Neill (2009) has argued that the Gobbi approach is essentially equivalent to the SDA/FMC since both rely on fundamental spectral curvature mechanisms to extract an analogous set of fine-mode parameters.

The GSM model was also applied to the NOAA CRD data by constructing the parameters $\stackrel{\circ}{a}_{\text {ep }}(355,1064)$ and $\delta \stackrel{\circ}{a}_{\text {ep }}=\stackrel{\circ}{a}_{\text {ep }}$ $(355,532)-\stackrel{\circ}{a}_{\text {ep }}(532,1064)$ from the four channels $(25 \%$ and $85 \% \mathrm{RH}$, sub 1 and sub $10 \mu \mathrm{m})$. Only the $25 \% \mathrm{RH}$ sub $1 \mu \mathrm{m}$ data yielded reasonable results and are presented below. As for the SDA/FMC method, we obtain two $R_{\text {eff,f }}$ values from the GSM approach, one using the AERONET data (hereafter
AERONET GSM) and one from the NOAA CRD data (hereafter CRD GSM).

\subsection{Meteorological conditions during the case study period}

The prevailing meteorological conditions characterizing the Houston/Galveston bay area were represented by Southerly winds (ESE to WSW) until 30 August 2006, followed by Northerly flow (N to NNE) until 6 September 2006, and winds between N-NE and ESE to WSW until mid September. Detailed information about these meteorological patterns and the properties of the corresponding air masses are reported in Wright et al. (2009) for the UHMT site and in Bates et al. (2008) and Massoli et al. (2009) for the RHB. Figure 1 illustrates the overall RHB track in the area during the field study (panel 1a), with an enlarged view of the ship tracks in Houston/Galveston Bay and the Houston ship channel (panel 1b).

Under the ESE winds, long range transport of Saharan dust was an important contributor to the bulk aerosol in the Gulf of Mexico based on aerosol chemical measurements and FLEXPART back trajectory analysis (Bates et al., 2008; Stohl and Eckhardt, 2008). One of the major Saharan dustintrusions occurred between 25 and 30 August 2006. Under prevailing Northerly flow, air masses over the Houston/Galveston Bay region and coastal Texas were a mixture of transport from the continental US and local/regional contributions. In particular, during the period 2-5 September, a long range transport event of sulfate aerosols from the Ohio River valley characterized a large region extending from Houston to coastal Texas and out in the Gulf of Mexico (Massoli et al., 2009). Examination of various datasets suggested that during both of these two particular periods, the RHB and the UHMT site were exposed to similar air 


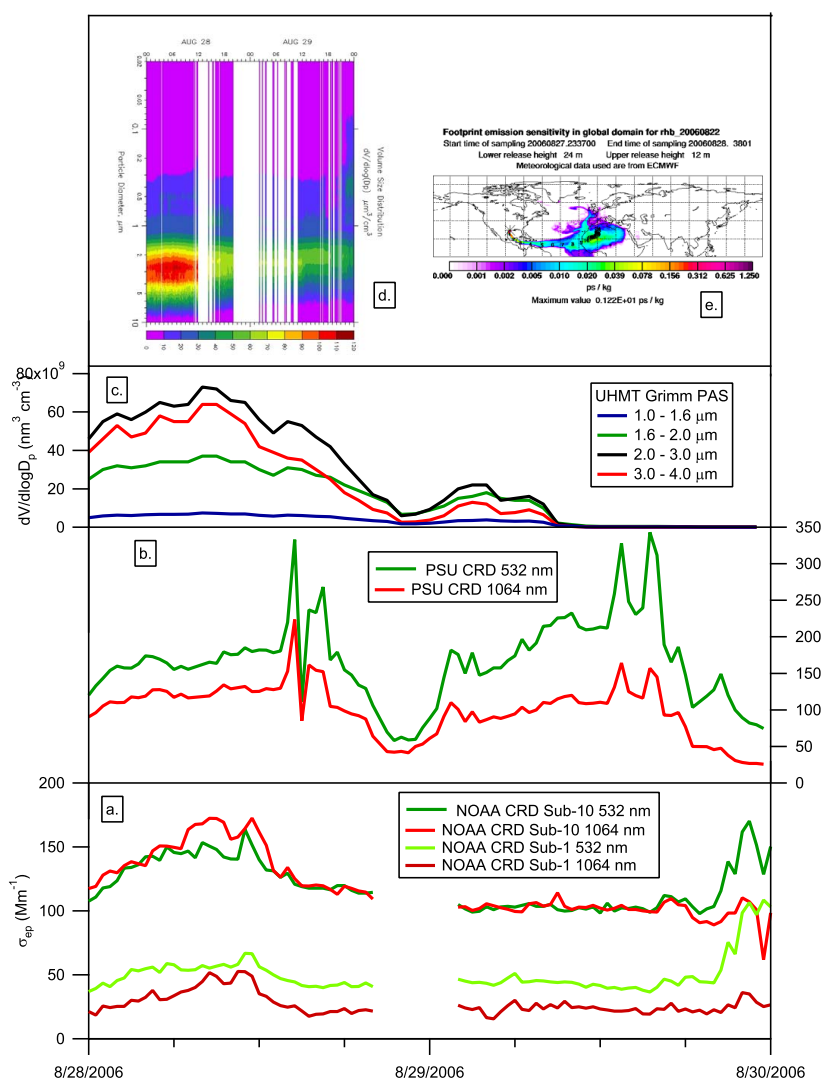

Fig. 2. Time series for the period 28 August-30 August 2006 of: panel (a) NOAA CRD sub 1 and sub $10 \mu \mathrm{m}, 85 \%$ RH, 532 and $1064 \mathrm{~nm} \sigma_{\mathrm{ep}}$; panel (b) PSU CRD 532 and $1064 \mathrm{~nm} \sigma_{\mathrm{ep}}$; panel (c) 1 to $4 \mu \mathrm{m}$, size bins of the PAS at the UHMT site; panel (d) volume concentration size distribution from the DMPS/APS on the RHB; and (e) FLEXPART trajectory analysis showing transport patterns from the Saharan region to the Gulf of Mexico on 27 August.

masses. In particular, the Community Multiscale Air Quality (CMAQ) model, initiated with the National Center for Environmental Prediction (NCEP) weather forecast and the National Emission Inventory (NEI '99) predicts large scale homogeneity in the aerosol for several extended periods in early September, including the period taken into account here (Byun and Lee, personal communication, 2009).

\section{Results and discussion}

\subsection{Data overview and investigation of spatial homogeneity}

Figures 2 and 3 give an overview of the data that were used in the analyses conducted here. Figure 2 refers to the period 28 August (00:00 UTC)-30 August (00:00 UTC) 2006, during the second major Saharan dust event observed over the Houston/Gulf of Mexico region. (All times referred to in the text and figures of this paper are UTC.) We show

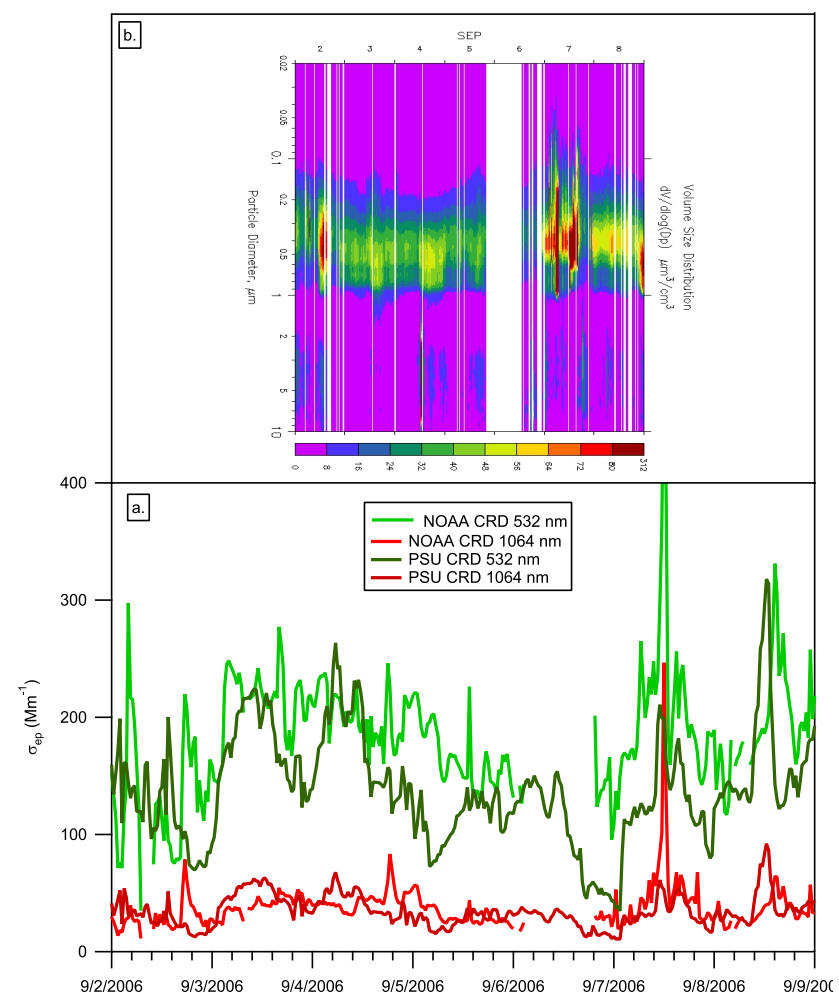

Fig. 3. Time series for the period 2-9 September 2006 of: panel (a) NOAA CRD 532 and $1064 \mathrm{~nm}$ sub 1 micron 85\% RH $\sigma_{\text {ep }}$ and PSU CRD 532 and $1064 \mathrm{~nm} \sigma_{\mathrm{ep}}$; and (b) volume concentration size distribution from the DMPS/APS on the RHB.

the $30 \mathrm{~min}$ average time series of 532 and $1064 \mathrm{~nm}$ NOAA CRD $\sigma_{\text {ep }}$ coefficients for the sub 1 and sub $10 \mu \mathrm{m}$ aerosols at $85 \% \mathrm{RH}$ (panel a); 532 and $1064 \mathrm{~nm}$ PSU CRD $\sigma_{\text {ep }}$ data for sub $4 \mu \mathrm{m}$ aerosols at the nominal 50\% RH (panel b); the coarse $(>1 \mu \mathrm{m})$ aerosol size distributions as measured by the GRIMM PAS at the UHMT site (panel c); the full volume size distribution from the DMPS/APS on the RHB (panel d); and the FLEXPART footprint emission sensitivity (panel e). After 27 August (18:00 UTC) a significant relative enhancement in the $1064 \mathrm{~nm}$ sub- $10 \mu \mathrm{m} \sigma_{\text {ep }}$ coefficient was observed by the NOAA CRD, suggesting a substantial increase in the coarse aerosol load. During the same time, the PSU CRD recorded higher $\sigma_{\text {ep }}$ levels at both 532 and $1064 \mathrm{~nm}$, although in this case the $\sigma_{\mathrm{ep}, 1064}<\sigma_{\mathrm{ep}, 532}$, perhaps due to the different size cuts of the CRD instruments $(10 \mu \mathrm{m}$ for the NOAA CRD and $4 \mu \mathrm{m}$ for the PSU CRD). The mobility size distribution data from both the UHMT and RHB showed that the $>1 \mu \mathrm{m}$ volume concentration peaked on 28 August with a maximum at approximately $3 \mu \mathrm{m}$, consistent with the presence of coarse dust particles in the area.

Figure 3 shows data for the period 2-9 September 2006 when the Houston/Galveston bay region was characterized by continental outflow under N-NE winds. The bottom panel shows the 532 and $1064 \mathrm{~nm} \sigma_{\text {ep }}$ time series data for 


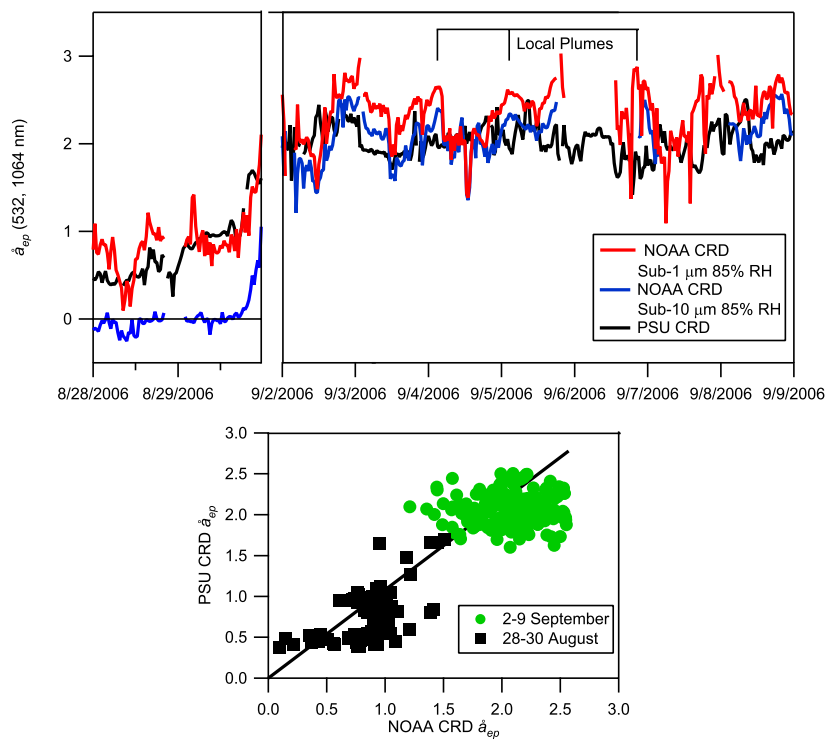

Fig. 4. Top: extinction Ångström exponents å ap obtained according to Eq. (2) using the 532 and $1064 \mathrm{~nm} \sigma_{\text {ep }}$ coefficients from the PSU CRD (black trace) and from the NOAA CRD at $85 \%$ RH for both sub $1 \mu \mathrm{m}$ (red trace) and sub $10 \mu \mathrm{m}$ (blue trace), for the two periods discussed in the text. Bottom: scatter plot of the PSU CRD

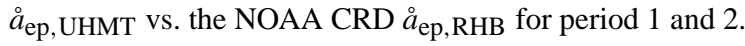

the NOAA CRD sub $1 \mu \mathrm{m} 85 \% \mathrm{RH}$ channel and the PSU CRD. Overall high $\sigma_{\text {ep }}$ levels were observed, with the $532 \mathrm{~nm}$ $\sigma_{\text {ep }}>100 \mathrm{Mm}^{-1}$ and the $1064 \mathrm{~nm} \sigma_{\text {ep }}$ coefficients around $50 \mathrm{Mm}^{-1}$. The volume size distributions collected on board the RHB (top panel) show that the particles were mostly in the accumulation mode, peaking between 300 and $400 \mathrm{~nm}$ particle mobility diameter. Organic matter and sulfate were present in equal amounts for the latter half of the period, while during 2-5 September sulfate aerosols were the dominant type and a regional haze event occurred in the Gulf region (Massoli et al., 2009). The quantitative agreement between the $\sigma_{\text {ep }}$ coefficients measured by the NOAA and PSU CRD instruments, with both large and small scale structures captured by the two CRDs, is noteworthy given that the physical distance between the two platforms reached 50 miles at times during this period. This confirms that the air masses probed at the two platforms (RHB and UHMT) were similar on a regional scale, as predicted by the NCEP/CMAQ models (Byun and Lee, personal communication, 2009).

Figure 4 shows the $\stackrel{\circ}{a}_{\text {ep,UHMT }}$ and $\stackrel{\circ}{\text { ep, RHB }}_{\text {calculated from }}$ the PSU and the $85 \%$ RH sub 1 and sub $10 \mu \mathrm{m}$ NOAA CRD $\sigma_{\text {ep }}$ data for 28-30 August (period 1, coarse mode dominated) and 2-9 September (period 2, fine mode dominated). The indicated areas during period 2 represent times when the data are known to be affected by local pollution plume sources sampled by RHB in the Galveston area. The

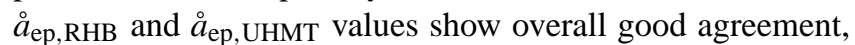
both qualitatively and quantitatively. A scatter plot of the

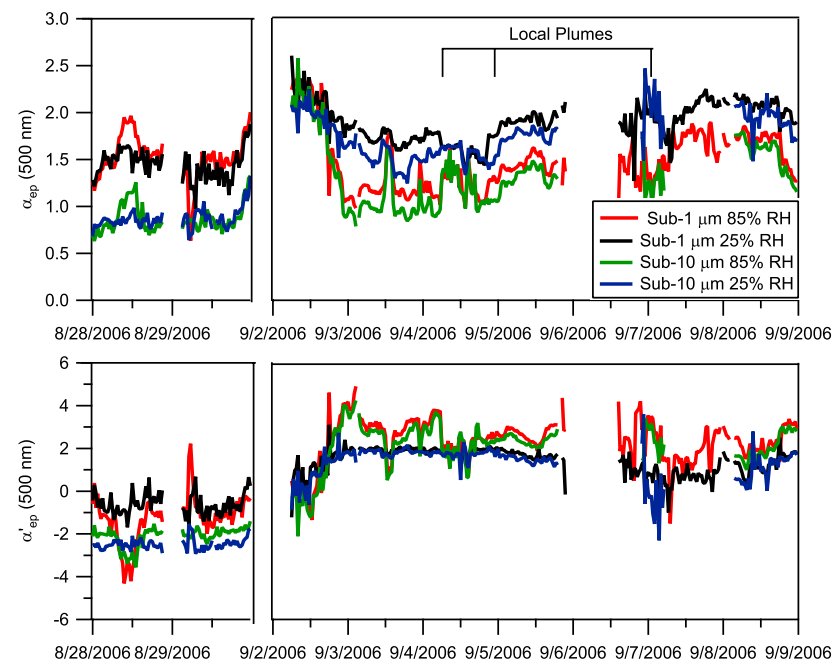

Fig. 5. The extinction Ångström exponent $\alpha_{\text {ep }}$ (top panel), and spectral curvature $\alpha_{\text {ep }}^{\prime}$ (bottom panel) for the sub 1 and sub $10 \mu \mathrm{m}$ NOAA CRD $\sigma_{\text {ep }}$ coefficients at $25 \%$ and $85 \% \mathrm{RH}$, extracted at $500 \mathrm{~nm}$ via the AERONET SDA/FMC routine.

PSU CRD vs. the NOAA CRD data (sub $1 \mu \mathrm{m}$ in period 1 and sub $10 \mu \mathrm{m}$ in period 2) is shown in the lower panel of

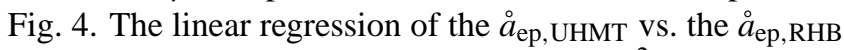
data leads to a overall slope of 0.96 , with an $R^{2}$ value of 0.75 . Again, this implies that there was large scale aerosol airmass consistency during this part of the study.

\section{2 Ångström exponent and spectral curvature analysis of the NOAA CRD data}

Figure 5 shows the $\alpha_{\text {ep }}$ (top panel) at $\lambda=500 \mathrm{~nm}$ and $\alpha_{\text {ep }}^{\prime}$ (bottom panel) extracted from the NOAA CRD data with the SDA/FMC procedure as described in Sect. 2.2. The $\alpha_{\text {ep }}$ and $\alpha_{\text {ep }}^{\prime}$ are presented for all the NOAA CRD data, i.e., sub 1 and sub $10 \mu \mathrm{m}$, and $25 \%$ and $85 \% \mathrm{RH}$, for both periods 1 and 2 .

Some interesting features emerge from the analysis. For period 1 (coarse mode dominated), the average value of $\alpha_{\mathrm{ep}}$ for the sub $1 \mu \mathrm{m}$ data is 1.5 , whereas the $\alpha_{\mathrm{ep}}$ value for sub $10 \mu \mathrm{m}$ is around 0.8 . No significant difference is observed between $\alpha_{\text {ep }}$ extracted at different RH; the $\alpha_{\text {ep }}$ reported for the $<1 \mu \mathrm{m}$ sizes at $25 \% \mathrm{RH}$ is approximately the same as that for the sub $1 \mu \mathrm{m}$ data at $85 \% \mathrm{RH}$. The minimal difference between $\alpha_{\text {ep }}$ values obtained at 25\% and $85 \%$ RH during the dust event indicates minimal water uptake even by the sub $1 \mu \mathrm{m}$ aerosols, as the aerosol sample was dominated by mineral dust in both size ranges. The analysis of impactor data collected on the RHB between 28 and 30 August shows that sub $1 \mu \mathrm{m}$ dust contributed up to $50 \%$ of the $<1 \mu \mathrm{m}$ aerosol mass (the rest being non sea-salt sulfate), whereas it was more than $80 \%$ of the total sub $10 \mu \mathrm{m}$ aerosol mass.

During period 2, the trend in the extracted $\alpha_{\text {ep }}$ values is different. In this case we observe similar $\alpha_{\text {ep }}$ values extracted for the same RH with no distinction between inlet size cut to 


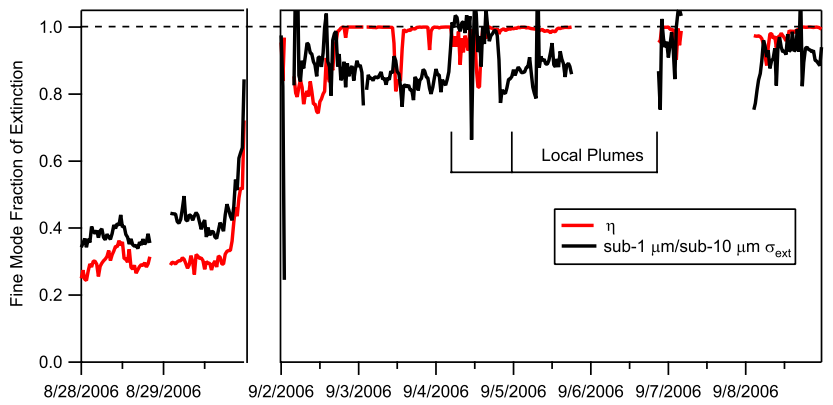

Fig. 6. Fine mode fraction of extinction $\eta$ at $500 \mathrm{~nm}$ calculated from the NOAA CRD $85 \% \mathrm{RH} \sigma_{\text {ep }}$ coefficients using the SDA/FMC method (red trace) and the ratio of the sub $1 \mu \mathrm{m}$ to the sub $10 \mu \mathrm{m}$ $85 \%$ RH $532 \mathrm{~nm} \sigma_{\text {ep }}$ data (black trace).

a first approximation: $\alpha_{\mathrm{ep}} \sim 1.2$ for $85 \% \mathrm{RH}$ data (both sub 1 and sub $10 \mu \mathrm{m}$ ) and $\alpha_{\mathrm{ep}} \sim 2.0$ for $25 \% \mathrm{RH}$ data (again both sub 1 and sub $10 \mu \mathrm{m})$. These results indicate the dominance of sub $1 \mu \mathrm{m}$ aerosols during period 2, with larger sizes (corresponding to the lower $\alpha_{\text {ep }}$ values at $85 \% \mathrm{RH}$ ) mainly due to particle hygroscopic growth (Massoli et al., 2009).

The curvature data $\alpha_{\text {ep }}^{\prime}$ (bottom panel of Fig. 5) reflect the trends discussed above for $\alpha_{\mathrm{ep}}$. During the coarse-mode dominated period, near-zero $\alpha_{\mathrm{ep}}^{\prime}$ is observed for the sub $1 \mu \mathrm{m}$ data $(25 \%$ and $85 \% \mathrm{RH})$, and negative values are obtained for sub $10 \mu \mathrm{m}$ data $(25 \%$ and $85 \% \mathrm{RH})$. For the fine-mode dominated Period 2, positive $\alpha_{\text {ep }}^{\prime}$ values of $\sim 1.8$ and 2.5 (average values) are obtained for the $85 \% \mathrm{RH}$ data (sub 1 and sub $10 \mu \mathrm{m}$ ) and for the $25 \% \mathrm{RH}$ data (sub 1 and sub $10 \mu \mathrm{m}$ ) respectively.

\subsection{Fine mode fraction $(\eta)$ and $\boldsymbol{R}_{\text {eff,f }}$ retrievals and com- parisons}

Here we describe the results of the spectral analysis conducted on the NOAA CRD data to obtain the fine mode $\eta$ and

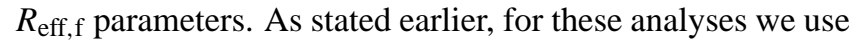
the sub $10 \mu \mathrm{m} 85 \%$ RH CRD data because it is closest to the ambient RH values. To further facilitate comparison between the AERONET and CRD retrievals, all of the parameters are reported at $500 \mathrm{~nm}$. Figure 6 shows the fine mode fraction $\eta$ extracted from the NOAA CRD data using the SDA/FMC procedure (red trace) for the two time periods shown earlier. In addition the ratio of the NOAA CRD $85 \% \mathrm{RH}$ sub $1 \mu \mathrm{m}$ to the sub $10 \mu \mathrm{m} \sigma_{\mathrm{ep}}$ coefficients (hereafter "SMF", or "submicron fraction") is shown in Fig. 6 (black trace). The SDA retrieval of the fine mode contribution to the total extinction gives general agreement with the SMF $(\eta \sim 0.95$ and SMF $\sim 0.9$ ) during period 2 and similar agreement $(\eta \sim 0.3$ and SMF 0.4) during the coarse mode event. In general one would expect $\eta$ to be slightly less than SMF due to the manner in which these parameters are calculated (cf., Kleidman et al., 2005 for example). Small spectral artifacts in the extinction data can lead to significant errors in $\eta$ because there

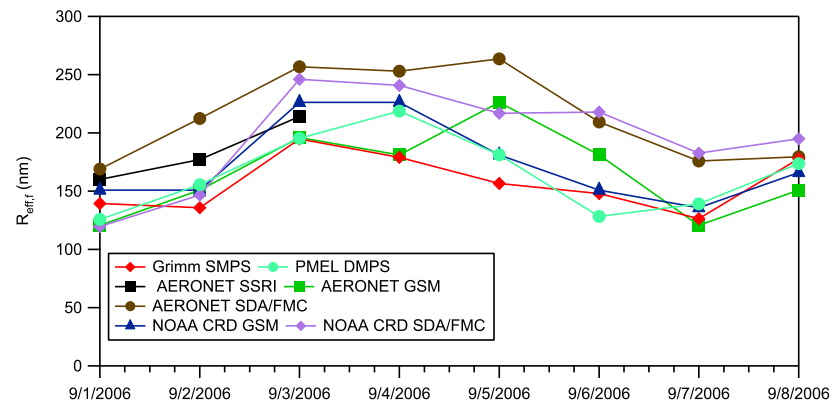

Fig. 7. Comparison of 24-hour average $R_{\mathrm{eff}, \mathrm{f}}$ values obtained from the NOAA CRD $\sigma_{\mathrm{ep}}$ data and from the AERONET sunphotometer using the spectral methods (SSRI is the full sun-sky radiance inversion used by AERONET V2, and the GSM and SDA/FMC methods are extensively discussed in the text), and the $R_{\text {eff, }}$ values estimated from the size distribution instruments (Grimm SMPS and PMEL DMPS).

are only three wavelengths used to determine the curvature (unlike the AERONET data which is overdetermined). In the case of the data shown in Fig. 6 during period 2, there are times where $\eta$ is unity and SMF does not attain this value. Because the DMPS/APS data in Fig. 3 confirms the dominance of fine mode particles during these periods, we suggest that this diescrepancy could be an artifact of the CRD's impactor-based separation that makes it difficult for SMF to assume unity or near-unity values.

In general, estimates of $R_{\text {eff,f }}\left(\rho_{\text {eff,f }}\right)$ become less accurate as $\eta$ decreases. Because we want to minimize the influence of retrieval results other than those related to the variation of $R_{\text {eff,f, we will only use the fine mode dominated period to }}$

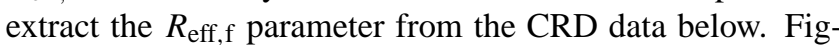
ure 7 depicts values of the fine mode effective mean radius

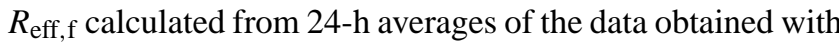
the various instruments, via the different methods discussed above, for the period 1-9 September 2006 slightly beyond the fine mode dominated event (2-5 September) discussed in Massoli (2009). We show $R_{\text {eff,f }}$ extracted from: the in situ NOAA CRD data via the SDA/FMC and GSM approaches (CRD SDA/FMC and CRD GSM, respectively) and from the AERONET sunphotometer data via the full sun/sky radiance inversion in AERONET V2, and the SDA/FMC and GSM approaches (AERONET SSRI, SDA/FMC and AERONET GSM, respectively). For the SDA/FMC treatment, the $R_{\text {eff,f }}$ was calculated from Eq. (8) using sub $1 \mu \mathrm{m} 85 \% \mathrm{RH} \rho_{\text {eff,f }}$ and a value for the refractive index broadly applicable to ambient aerosols, $m=1.4-0.001 i$ (Gobbi et al., 2007). The pair-wise $\stackrel{\circ}{a}$ and $\delta \stackrel{\circ}{a}$ values from the sub $1 \mu \mathrm{m} 25 \%$ RH NOAA CRD data were constructed and placed on the grid shown in Fig. 1 of Gobbi et al. (2007) to extract the geometric fine mode radius, which was then converted to the effective radius for Fig. 7 . The last two reported $R_{\text {eff,f }}$ datasets are calculated using a numerical evaluation of Eq. (1) from 
Table 1. The correlation coefficient $\left(R^{2}\right)$ and the slope and intercept of the various measures of $R_{\text {eff,f }}$ from an orthogonal distance regression (ODR) between the pairs (row vs. column). For an ODR, the slope of the reversed regression is necessarily the inverse (hence only half of the matrix is given). Note that there are only three AERONET points for these comparisons, so the (italicized) correlation coefficients are artificially close to one. The intercept has units of $\mathrm{nm}$.

\begin{tabular}{|c|c|c|c|c|c|c|}
\hline $\begin{array}{l}R^{2}, \\
\text { slope, } \\
\text { intercept }\end{array}$ & $\begin{array}{l}\text { Grimm } \\
\text { SMPS }\end{array}$ & $\begin{array}{l}\text { PMEL } \\
\text { DMPS }\end{array}$ & $\begin{array}{l}\text { AERONET } \\
\text { V2 }(N=3)\end{array}$ & $\begin{array}{l}\text { AERONET } \\
\text { GSM }\end{array}$ & $\begin{array}{l}\text { AERONET } \\
\text { SDA/FMC }\end{array}$ & $\begin{array}{l}\text { CRD } \\
\text { GSM }\end{array}$ \\
\hline $\begin{array}{l}\text { CRD } \\
\text { SDA/FMC }\end{array}$ & $0.72,0.45,70$ & $0.70,0.67,34$ & $0.99,0.41,113$ & $0.75,0.78,13$ & $0.74,0.83,53$ & $0.73,0.73,31$ \\
\hline $\begin{array}{l}\text { CRD } \\
\text { GSM }\end{array}$ & $0.88,0.66,43$ & $0.90,0.94,1.0$ & $0.95,0.62,74$ & $0.63,1.08,-22$ & $0.79,1.13,19$ & - \\
\hline $\begin{array}{l}\text { AERONET } \\
\text { SDA/FMC }\end{array}$ & $0.57,0.46,57$ & $0.76,0.82,-12$ & $0.98,0.62,51$ & $0.91,0.95,-38$ & - & - \\
\hline $\begin{array}{l}\text { AERONET } \\
\text { GSM }\end{array}$ & $0.56,0.49,76$ & $0.59,0.84,25$ & $0.99,0.73,70$ & - & - & - \\
\hline $\begin{array}{l}\text { AERONET } \\
\text { V2 }(N=3)\end{array}$ & $0.93,1.21,-66$ & $0.99,1.27,-74$ & - & - & - & - \\
\hline $\begin{array}{l}\text { PMEL } \\
\text { DMPS }\end{array}$ & $0.80,0.67,46$ & - & - & - & - & - \\
\hline
\end{tabular}

the in situ size distribution measurements at the UHMT site (hereafter Grimm SMPS) and on the RHB (hereafter PMEL DMPS). The sub- $1 \mu \mathrm{m}$ particle size distribution data were averaged to 24-h periods and the data were summed bin-wise for $\left(d N x \pi r_{\text {bin }}^{3}\right)$ and $\left(d N x \pi r_{\text {bin }}^{2}\right)$ and then ratioed to produce the Grimm SMPS and PMEL DMPS $R_{\text {eff,f }}$ estimates.

The $R_{\text {eff,f }}$ estimates obtained from the various methods span a range of approximately $100 \mathrm{~nm}$, centered near $200 \mathrm{~nm}$, with a pooled standard deviation of $28 \mathrm{~nm}$ (taking each day as a set). All of the in situ methods captured the rapid increase in $R_{\text {eff,f }}$ during the first days of September 2006 and then the stable higher radius during the middle of the period. The agreement between the in situ size distribution derived $R_{\text {eff,f }}$ values GRIMM SMPS and PMEL DMPS is better during 2-5 September, when the size distributions peaked at a small radius. This provides additional evidence that a synoptic scale airmass was being observed at both platforms. The low bias of the Grimm SMPS measurements may be from an intentional choice to limit the size range to a particle diameter of $521 \mathrm{~nm}$ because of concern that the few larger size bins may have been contaminated by small particle count data. As the particle mean radius may have approached $250 \mathrm{~nm}$ during the latter part of this period, this choice almost certainly excluded some particle sizes that were relevant to the evaluation of $R_{\text {eff,ff }}$. The $R_{\text {eff,f }}$ values from the sunphotometer based size distribution produced by AERONET seem to also agree rather well with GRIMM SMPS and PMEL DMPS values, suggesting a certain level of homogeneity in the size distribution throughout the column or dominance of the surface extinction. Unfortunately the AERONET full sky scan data was missing after 3 September because of cloud contamination, limiting these comparisons.
The agreement between the $R_{\text {eff,f }}$ values obtained from AERONET AOD and NOAA CRD $\sigma_{\text {ep }}$ data via the spectral methods is also compelling; however, the SDA/FMC-based $R_{\text {eff,f }}$ values are systematically higher than the GSM-based ones. In order to provide more quantitative comparisons we performed pair-wise orthogonal distance regressions (an unbiased regression that allows for errors in both datasets being compared, as implemented in the IgorPro software using the /ODR switch with the CurveFit command) between the $R_{\text {eff,f }}$ estimates from the various methods as shown in Table 1 . Since we do not assert that any specific method is better than others for determining $R_{\text {eff,f, the ODR analysis }}$ allows an unbiased comparison. The correlation coefficients reflect the level of covariance of the different methods to estimate $R_{\text {eff,f }}$ values, whereas the slopes and intercepts from the ODR can be used to estimate relative method biases. The apparent low bias (slope $=0.67$ ) in the PMEL DMPS is probably due to the lower RH (60\%) used for these measurements. The slight low bias (slope $=0.73$ ) in the comparison between the SDA/FMC and the GSM for the CRD data may be due to the use of different wavelengths (vs. those used by Gobbi et al., 2007) since this bias is not observed between the two methods when applied to the AERONET AOD data. 


\section{Conclusions}

The purpose of this study was to assess the possibility of using multi-wavelength in situ aerosol $\sigma_{\text {ep }}$ measurements to extract information pertaining to the fine mode fraction of extinction $\eta$ and the fine mode effective radius $R_{\text {eff, } \mathrm{f}}$ in a fashion similar to that used with columnar AOD measurements (such as those from the AERONET sunphotometers or satellite borne sensors). This information is potentially useful for partitioning the contributions of anthropogenic (mostly present in the fine mode) and natural (larger coarse mode contribution) aerosols to the measured $\sigma_{\text {ep }}$ coefficients.

There was agreement between the fine mode fraction and $R_{\text {eff,f }}$ results obtained from the different methods. The agreement of the SDA-derived $\eta$ with the SMF (Fig. 6) suggests that the method is robust, especially since it was run for a sub optimal number of wavelengths (three is the minimum usable). This is useful for helping to validate the SDA AERONET product and also suggests that the wavelength dependence of extinction from the CRD can provide a reasonable estimate for the partitioning between the fine and coarse modes.

The $R_{\text {eff,f }}$ retrieval from the wavelength dependent optical measurements also appears to be promising. While the GSM method is simple and provides qualitative information, it is difficult to apply in a quantitative way mainly because graphically interpreting a large amount of time-resolved data to obtain values for $\eta$ and $R_{\text {eff,f }}$ is impractical. The production of $\eta$ and $\rho_{\text {eff,f }}$ by the SDA/FMC algorithm is efficient and is probably a more reasonable approach since it properly leaves the $R_{\text {eff,f }}$ and refractive index information intertwined. Although there currently are no universally accepted measurements of particle refractive index applied to ambient aerosols in field studies, there are a number of potentially useful surrogates, including using literature recommended values as used here, or the refractive index product from the AERONET V2. The ability to extract $R_{\text {eff,f }}$ would significantly expand the utility of the in situ CRD instrument's optical measurements of $\sigma_{\text {ep }}$ at multiple wavelengths, which are currently being deployed on land, ship, and aircraft, but typically only during field-intensive periods. A new generation of low-cost, portable instruments that measure $\sigma_{\text {ep }}$ with accuracy and precision similar to state of the art methods such as CRD are being developed and deployed (cf., Massoli et al., Aerosol light extinction measurements by Cavity Attenuated Phase Shift Spectroscopy (CAPS): laboratory validation and field deployment of a compact aerosol extinction monitor, submitted, AST) to achieve a wider coverage of aerosol optical property measurements. If similar data analyses could be performed on a wider spatial scale, they could provide useful information about fine mode physical and optical properties for use in radiative forcing calculations and indirect effect estimates that are currently needed for global climate change models.
Acknowledgements. The TRAMP participants, DBA, SDB, and $\mathrm{BL}$ would like to express their gratitude to the Houston Advanced Research Center (HARC) for supporting and funding Project H78 and the Texas Commission on Environmental Quality (TCEQ) for supporting and funding this research under grant 582-5-64594. DBA acknowledges support from the Atmospheric Composition and Climate program at the National Atmospheric and Oceanic Administration through award number NA05OAR4310108. The authors also thank the officers and crew of the NOAA RV Ronald H. Brown, the NOAA Climate and Global Change Program, the NOAA Office of Oceanic and Atmospheric Research, the NOAA Health of the Atmosphere Program, and the Texas Air Quality Study.

Edited by: M. Petters

\section{References}

IPCC, 2007: Climate Change 2007: The Physical Science Basis. Contribution of Working Group I to the Fourth Assessment Report of the Intergovernmental Panel on Climate Change Cambridge, UK and New York, NY, USA.

Anderson, T. L., Charlson, R. J., Bellouin, N., Boucher, O., Chin, M., Christopher, S. A., Haywood, J., Kaufman, Y. J., Kinne, S., Ogren, J. A., Remer, L. A., Takemura, T., Tanre, D., Torres, O., Trepte, C. R., Wielicki, B. A., Winker, D. M., and Yu, H. B.: An "A-Train" strategy for quantifying direct climate forcing by anthropogenic aerosols, B. Am. Meteorol. Soc., 86, 1795-1810, 2005.

Andreae, M. O., Rosenfeld, D., Artaxo, P., Costa, A. A., Frank, G. P., Longo, K. M., and Silva-Dias, M. A. F.: Smoking rain clouds over the Amazon, Science, 303, 1337-1342, 2004.

Ångström, A.: On the atmospheric transmission of sun radiation and on dust in the air, Geografika Ann., 11, 156-166, 1929.

Atkinson, D. B.: Solving chemical problems of environmental importance using cavity ring-down spectroscopy, The Analyst, 128, 117-125, 2003.

Bates, T. S., Coffman, D. J., Covert, D. S., and Quinn, P. K.: Regional marine boundary layer aerosol size distributions in the Indian, Atlantic, and Pacific Oceans: A comparison of INDOEX measurements with ACE-1, ACE-2, and Aerosols99, J. Geophys. Res.-Atmos., 107, 8026, doi:10.1029/2001JD001174, 2002.

Bates, T. S., Anderson, T. L., Baynard, T., Bond, T., Boucher, O., Carmichael, G., Clarke, A., Erlick, C., Guo, H., Horowitz, L., Howell, S., Kulkarni, S., Maring, H., McComiskey, A., Middlebrook, A., Noone, K., O’Dowd, C. D., Ogren, J., Penner, J., Quinn, P. K., Ravishankara, A. R., Savoie, D. L., Schwartz, S. E., Shinozuka, Y., Tang, Y., Weber, R. J., and Wu, Y.: Aerosol direct radiative effects over the northwest Atlantic, northwest Pacific, and North Indian Oceans: estimates based on in-situ chemical and optical measurements and chemical transport modeling, Atmos. Chem. Phys., 6, 1657-1732, 2006, http://www.atmos-chem-phys.net/6/1657/2006/.

Baynard, T., Lovejoy, E. R., Pettersson, A., Brown, S. S., Lack, D., Osthoff, H., Massoli, P., Ciciora, S., Dube, W. P., and Ravishankara, A. R.: Design and application of a pulsed cavity ringdown aerosol extinction spectrometer for field measurements, Aerosol Sci. Tech., 41, 447-462, 2007. 
Berner, A., Lurzer, C., Pohl, F., Preining, O., and Wagner, P.: Size Distribution of the Urban Aerosol in Vienna, Sci. Total Environ., 13, 245-261, 1979.

Chin, M., Chu, A., Levy, R., Remer, L., Kaufman, Y., Holben, B., Eck, T., Ginoux, P., and Gao, Q. X.: Aerosol distribution in the Northern Hemisphere during ACE-Asia: Results from global model, satellite observations, and Sun photometer measurements, J. Geophys. Res.-Atmos., 109(15), D23S90, doi:10.1029/2004jd004829, 2004.

Doherty, S. J., Quinn, P. K., Jefferson, A., Carrico, C. M., Anderson, T. L., and Hegg, D.: A comparison and summary of aerosol optical properties as observed in situ from aircraft, ship, and land during ACE-Asia, J. Geophys. Res.-Atmos., 110, D04201, doi:10.1029/2004jd004964, 2005.

Dubovik, O. and King, M. D.: A flexible inversion algorithm for retrieval of aerosol optical properties from Sun and sky radiance measurements, J. Geophys. Res., 105, 20673-20696, 2000.

Dubovik, O., Holben, B. N., Lapyonok, T., Sinyuk, A., Mishchenko, M. I., Yang, P., and Slutsker, I.: Non-spherical aerosol retrieval method employing light scattering by spheroids, Geophys. Res. Lett., 29(4), 1415 doi:10.1029/2001gl014506, 2002.

Dubovik, O., Sinyuk, A., Lapyonok, T., Holben, B. N., Mishchenko, M., Yang, P., Eck, T. F., Volten, H., Munoz, O., Veihelmann, B., van der Zande, W. J., Leon, J. F., Sorokin, M., and Slutsker, I.: Application of spheroid models to account for aerosol particle nonsphericity in remote sensing of desert dust, J. Geophys. Res.-Atmos., 111(34), D11208, doi:10.1029/2005jd006619, 2006.

Gobbi, G. P., Kaufman, Y. J., Koren, I., and Eck, T. F.: Classification of aerosol properties derived from AERONET direct sun data, Atmos. Chem. Phys., 7, 453-458, 2007, http://www.atmos-chem-phys.net/7/453/2007/.

Hansen, J. E. and Travis, L. D.: Light Scattering in Planetary Atmospheres, Space Sci. Rev., 16, 527-610, 1974.

Holben, B. N., Eck, T. F., Slutsker, I., Tanré, D., Buis, J. P., Setzer, A., Vermote, E., Reagan, J. A., Kaufman, Y. J., Nakajima, T., Lavenu, F., Jankowiak, I., and Smirnov, A.: AERONET - A federated instrument network and data archive for aerosol characterization, Rem. Sens. Env., 66, 1-16, 1998.

Kleidman, R. G., O’Neill, N. T., Remer, L. A., Kaufman, Y. J., Eck, T. F., Tanre, D., Dubovik, O., and Holben, B. N.: Comparison of moderate resolution Imaging spectroradiometer (MODIS) and aerosol robotic network (AERONET) remote-sensing retrievals of aerosol fine mode fraction over ocean, J. Geophys. Res.Atmos., 110(6), D22205, doi:10.1029/2005jd005760, 2005.

Lefer, B. and Rappenglück, B.: Overview of TRAMP Texas II Study, Atmos. Environ., in preparation, 2010.

Lohmann, U. and Feichter, J.: Global indirect aerosol effects: a review, Atmos. Chem. Phys., 5, 715-737, 2005, http://www.atmos-chem-phys.net/5/715/2005/.

Massoli, P., Bates, T. S., Quinn, P. K., Lack, D. A., Baynard, T., Lerner, B. M., Tucker, S. C., Brioude, J., Stohl, A., and Williams, E. J.: Aerosol optical and hygroscopic properties during TexAQS-GoMACCS 2006 and their impact on aerosol direct radiative forcing, J. Geophys. Res.-Atmos., 114(17), D00F07, doi:10.1029/2008jd011604, 2009.
Moosmuller, H., Varma, R., and Arnott, W. P.: Cavity ringdown and cavity-enhanced detection techniques for the measurement of aerosol extinction, Aerosol Sci. Tech., 39, 30-39, doi:10.1080/027868290903880, 2005.

O’Neill, N. T., Eck, T. F., Smirnov, A., Holben, B. N., and Thulasiraman, S.: Spectral discrimination of coarse and fine mode optical depth, J. Geophys Res.-Atmos., 108(15), 4559, doi:10.1029/2002jd002975, 2003.

O’Neill, N. T., Thulasiraman, S., Eck, T. F., and Reid, J. S.: Robust optical features of fine mode size distributions: Application to the Quebec smoke event of 2002, J. Geophys Res.-Atmos., 110(21), D11207, doi:10.1029/2004jd005157, 2005.

O’Neill, N. T., Thulasiraman, S., Eck, T. F., and Reid, J. S.: Correction to "Robust optical features of fine mode size distributions: Application to the Québec smoke event of 2002", J. Geophys. Res., 113, D24203, doi:10.1029/2008JD011334, 2008.

O'Neill, N. T.: Comment on "Classification of aerosol properties derived from AERONET direct sun data" edited by: Gobbi, G. P., et al. (2007), Atmos. Chem. Phys. Discuss., 9, 175-182, 2009, http://www.atmos-chem-phys-discuss.net/9/175/2009/.

Radney, J. G., Bazargan, M. H., Wright, M. E., and Atkinson, D. B.: Laboratory Validation of Aerosol Extinction Coefficient Measurements by a Field-Deployable Pulsed Cavity Ring-Down Transmissometer, Aerosol Sci. Technol., 43, 71-80, doi:10.1080/02786820802482536, 2009.

Schuster, G. L., Dubovik, O., and Holben, B. N.: Angstrom exponent and bimodal aerosol size distributions, J. Geophys Res.Atmos., 111(14), D07207, doi:10.1029/2005jd006328, 2006.

Sinyuk, A., Dubovik, O., Holben, B., Eck, T. F., Breon, F. M., Martonchik, J., Kahn, R., Diner, D. J., Vermote, E. F., Roger, J. C., Lapyonok, T., and Slutsker, I.: Simultaneous retrieval of aerosol and surface properties from a combination of AERONET and satellite data, Remote Sens. Environ., 107, 90108, doi:10.1016/j.rse.2006.07.022, 2007.

Strawa, A. W., Elleman, R., Hallar, A. G., Covert, D., Ricci, K., Provencal, R., Owano, T. W., Jonsson, H. H., Schmid, B., Luu, A. P., Bokarius, K., and Andrews, E.: Comparison of in situ aerosol extinction and scattering coefficient measurements made during the Aerosol Intensive Operating Period, J. Geophys Res.Atmos., 111(17), D05S03, doi:10.1029/2005jd006056, 2006.

Winklmayr, W., Reischl, G. P., Lindner, A. O., and Berner, A.: A New Electromobility Spectrometer for the Measurement of Aerosol Size Distributions in the Size Range from 1 to $1000 \mathrm{Nm}$, J. Aerosol Sci., 22, 289-296, 1991.

Yu, H., Kaufman, Y. J., Chin, M., Feingold, G., Remer, L. A., Anderson, T. L., Balkanski, Y., Bellouin, N., Boucher, O., Christopher, S., DeCola, P., Kahn, R., Koch, D., Loeb, N., Reddy, M. S., Schulz, M., Takemura, T., and Zhou, M.: A review of measurement-based assessments of the aerosol direct radiative effect and forcing, Atmos. Chem. Phys., 6, 613-666, 2006, http://www.atmos-chem-phys.net/6/613/2006/. 